\title{
Interleukin-6 Antisense Oligonucleotides Inhibit the Growth of Human Myeloma Cell Lines
}

Yves Levy, Andreas Tsapis, and Jean-Claude Brouet

Laboratory of Immunochemistry and Immunopathology, Institut National de la Santé

et de la Recherche Médicale U 108, Hôpital Saint-Louis, 75475 Paris Cedex 10, France

\begin{abstract}
IL-6 has been shown to be a plasmacytoma growth factor in mice and is believed to play a key role in the development of human multiple myeloma. We investigated the IL-6 requirements for the growth of two human myeloma cell lines, $U 266$ and RPMI 8226. These cell lines secreted minute amounts of IL-6 $(20 \mathrm{U} / \mathrm{ml})$ and featured IL-6 mRNA. IL-6 receptors were detectable at the surface of malignant cells by immunofluorescence. Antibodies to IL-6 did not alter the proliferation of these myeloma cells. There was a dose-dependent decrease, however, in $\left[{ }^{3} \mathrm{H}\right]$-thymidine uptake in the presence of IL-6 antisense (and not sense) oligodeoxynucleotides; in the presence of $20 \mu \mathrm{M}$ IL-6 antisense, an 80 and $95 \%$ inhibition of the proliferation of U 266 and RPMI 8226 cells was observed, respectively. These results provide strong evidence for an IL-6 autocrine proliferation of myeloma cells which may occur via internal interaction between IL-6 and the IL-6 receptor. (J. Clin. Invest. 1991. 88:696-699.) Key words: IL-6 • myeloma • autocrine growth
\end{abstract}

\section{Introduction}

IL-6 has pleiotropic effects on a variety of cell types (reviewed in 1). It has been initially characterized as a murine plasmacytoma growth factor $(2,3)$. This discovery led to important insights in the biology of human multiple myeloma (MM) ${ }^{1}$ since it was demonstrated that this lymphokine might have a crucial role in the proliferation of malignant plasma cells (4). However, the possibility of an IL-6 autocrine growth of myeloma cells is controversial since it has been shown that in most patients with MM the major source of IL-6 secretion is the bone marrow microenvironment, favoring a paracrine growth of plasma cells (5). In view of the technical difficulties of obtaining purified plasma cell preparations from bone marrows, it is

Address correspondence to Dr. J.-C. Brouet, Laboratory of Immunochemistry and Immunopathology, INSERM U 108, Bâtiment INSERM, Hôpital Saint-Louis, 1, avenue Claude Vellefaux, 75475 Paris Cedex 10, France.

Received for publication 25 January 1991 and in revised form 1 April 1991.

1. Abbreviations used in this paper: IL-6R, IL-6 receptor; MM, multiple myeloma; rIL-6, recombinant IL-6; $\left[{ }^{3} \mathrm{H}\right]-\mathrm{TdR},\left[{ }^{3} \mathrm{H}\right]$-thymidine.

J. Clin. Invest.

(c) The American Society for Clinical Investigation, Inc.

0021-9738/91/08/0696/04 \$2.00

Volume 88, August 1991, 696-699 likely to be extremely difficult to distinguish between genuine autocrine factor production from a paracrine pathway. We therefore investigated the IL- 6 requirements for growth of two well characterized human plasma cell lines, U 266 and RPMI 8226. Cells from both lines secreted minute amount of IL-6 and their proliferation was unaffected by neutralizing anti-IL-6 antibodies. Strikingly, myeloma cells proliferation was profoundly inhibited in the presence of IL-6 antisense oligonucleotides providing strong evidence for an autocrine IL-6-dependent growth.

\section{Methods}

Myeloma cell lines. U 266 (6) and RPMI 8226 (7) myeloma cell lines secreting IgE $\lambda$ and $\lambda$ molecules, respectively, were cultured in RPMI 1640 medium supplemented with $10 \%$ fetal bovine serum inactivated for $45 \mathrm{~min}$ at $65^{\circ} \mathrm{C}, 2 \mathrm{mM}$ L-glutamine, and antibiotics.

IL-6 sense and antisense oligonucleotides. A 15-base antisense oligodeoxynucleotide (TCCTGGGGGTACTGG) specific for a sequence in the second exon of the IL-6 gene $(8,9)$ was prepared (Genset, Paris, France). A control sense oligonucleotide was used in each experiment. Various concentrations $(2,10$, and $20 \mu \mathrm{M})$ of both oligonucleotides were tested. Oligonucleotides were purified by HPLC and electrophoresis on polyacrylamide gels.

Culture of $U 266$ and RPMI 8226 myeloma cells in the presence of IL- 6 antisense and sense oligonucleotides and anti-IL-6 antibodies. Myeloma cell lines were cultured for $6 \mathrm{~h}$ in serum-free medium. After three washes, cells were resuspended at $10^{4}$ cells in $0.1 \mathrm{ml}$ of culture medium containing $2.5 \%$ of fetal bovine serum and plated in 96-well plates for $48 \mathrm{~h}$. Various concentrations of IL-6 antisense and control IL- 6 sense oligonucleotides were added at the onset of the culture period. In some experiments purified goat anti-IL-6 neutralizing antibodies (generous gift from T. Hirano and T. Kishimoto, Osaka, Japan) at a 1:10,000 final dilution, or rabbit anti-IL-6 antibodies (10-30 $\mu \mathrm{g} / \mathrm{ml}$; Genzyme Corp., Boston, MA) were added at the beginning of the culture. Purified goat or rabbit IgG were used as controls. In another set of experiments, various concentrations of recombinant IL-6 (rIL-6) (Boehringer Mannheim GmbH, Mannheim, FRG) (10-100 pg/ml) were included in cell cultures containing IL- 6 antisense and sense nucleotides.

Cell proliferation was evaluated by $\left[{ }^{3} \mathrm{H}\right]$-thymidine $\left(\left[{ }^{3} \mathrm{H}\right]-\mathrm{TdR}\right)$ incorporation. $1 \mu \mathrm{Ci}$ of $\left[{ }^{3} \mathrm{H}\right]-\mathrm{TdR}$ was added for the final $8 \mathrm{~h}$ of the culture period and cells were harvested onto glass filter and counted on a liquid scintillation counter. Assays were done in triplicate.

IL-6 bioactivity. The IL- 6 content of U 266 and RPMI 8226 myeloma cells supernatants (when cultured at $1.10^{6}$ cells $/ \mathrm{ml}$ ) was measured using the IL-6-dependent B9 hybridoma cell line. B9 cells $\left(5 \cdot 10^{3}\right)$ were cultured for $72 \mathrm{~h}$ in the presence of triplicate serial dilutions of myeloma cell supernatants in 96-well plates. B9 cell proliferation was estimated by $\left[{ }^{3} \mathrm{H}\right]-\mathrm{TdR}$ incorporation. Human rIL- 6 was used as an internal standard in all assays. One reference unit of IL-6 was defined by the half-maximal proliferation of $\mathrm{B} 9$ cells, and corresponded reproductively to $1 \mathrm{pg}$ of rIL-6. 
Immunofluorescence. Cells from both myeloma lines were examined by immunofluorescence for the expression of IL-6R using two monoclonal antibodies (MT18 and PM1, $3 \mu \mathrm{g} / \mathrm{ml}$ ) kindly provided by T. Taga and T. Kishimoto, Osaka, Japan. Mouse antibodies were revealed with fluoresceinated $\mathrm{F}\left(\mathrm{ab}^{\prime}\right)^{2}$ fragments of rabbit IgG to mouse Ig prepared in our laboratory. Controls with mouse Ig of irrelevant specificity were negative.

DNA and RNA hybridization conditions. High molecular weight DNA of U 266 and RPMI 8226 cells was prepared as described (10). Total RNA was obtained by extraction with guanidine isothiocyanate and ultracentrifugation in cesium chloride (11). Restriction endonucleases were obtained from Boehringer Mannheim, and digestion of DNA was performed according to the manufacturer's instructions.

DNA fragments were separated by electrophoresis on $0.8 \%$ agarose gels and transferred to nylon filters (Hybond N; Amersham Corp., Arlington Heights, IL) according to the Southern method (12). RNA was blotted to nitrocellulose filters (Hybond C-E; Amersham). Prehybridization, hybridization, and washing were carried out as previously described (13). Films (X-OMAT AR; Kodak) were exposed at $-80^{\circ} \mathrm{C}$ for $3 \mathrm{~d}$.

Probes. IL-6 and IL-6 receptor (IL-6R) probes (a generous gift from Dr. T. Kishimoto), were ${ }^{32} \mathrm{P}$-labeled by the hexanucleotide random primer method (14), using a Boehringer kit and $\alpha-{ }^{32} \mathrm{P}$-labeled dCTP (Dupont de Nemours, France) at 3,000 Ci/mmol.

\section{Results}

We evaluated the IL-6 requirements for growth of two human myeloma cell lines, $U 266$ and RPMI 8226 secreting IgE $\lambda$ and $\lambda$ molecules, respectively. A twofold increase in $\left[{ }^{3} \mathrm{H}\right]-\mathrm{TdR}$ uptake was noted in the presence of $100 \mathrm{pg} / \mathrm{ml}$ of rIL-6 (data not shown, and see Fig. 3). The IL-6 content of supernatants from both cell lines cultured for $48 \mathrm{~h}$ at a concentration of $10^{6}$ cells/ $\mathrm{ml}$ was $20 \mathrm{U} / \mathrm{ml}$. A normal sized mRNA for IL-6 was detected in both lines (Fig. 1). IL-6R was detected by a fluorescence assay using two different MAb (MT18 and PM1) on over $90 \%$ U 266 and RPMI cells.

The spontaneous proliferation of U 266 and RPMI 8226 cells cultured for $48 \mathrm{~h}$ at a density of $10^{5} / \mathrm{ml}$ was unmodified in the presence of rabbit and/or goat neutralizing antibodies to IL-6 $\left(\left[{ }^{3} \mathrm{H}\right]-\mathrm{TdR}\right.$ uptake in the presence or absence of anti-IL-6 antibodies was 6,300 and $6,100 \mathrm{cpm}$ for $U 266$, and 33,200 and $36,800 \mathrm{cpm}$ for RPMI 8226). Similar results were also noted at lower cell density (data not shown).

At first, these latter results did not favor the possibility of an IL-6 autocrine proliferation of these myeloma cell lines. However, we found that in the presence of IL-6 antisense oligonucleotides, the growth of both lines was strikingly modified. Indeed, there was a dose-dependent decrease of $\left[{ }^{3} \mathrm{H}\right]-T d R$ uptake by $U$ 266 and RPMI 8226 cells. This inhibition was highly reproducible in eight different experiments; representative curves are shown in Fig. 2, $A$ and $B$. This effect was already significant at an oligonucleotide concentration as low as $2 \mu \mathrm{M}$ (50\% inhibition, range $25-70 \%$ ). At $15 \mu \mathrm{M}$, the mean inhibition was $72 \%$ (range 65-85\%). Inhibition of cell proliferation was maximal at $20 \mu \mathrm{M}$ (85\% inhibition, range $80-95 \%)$. Control sense oligonucleotides exhibited only marginal effects $(<25 \%$ inhibition at $20 \mu \mathrm{M}$ ). Supernatants from antisense (and not sense) oligonucleotides treated myeloma cells contained no detectable IL-6 bioactivity $(<5 \mathrm{U} / \mathrm{ml})$. Both oligonucleotides did not alter the T-derived MOLT4 cell line proliferation (Fig. $2 \mathrm{~A}$ ). The IL-6 antisense inhibition of myeloma cell proliferation was partly restored in the presence of $100 \mathrm{pg} / \mathrm{ml}$ of IL-6 (Fig. 3).

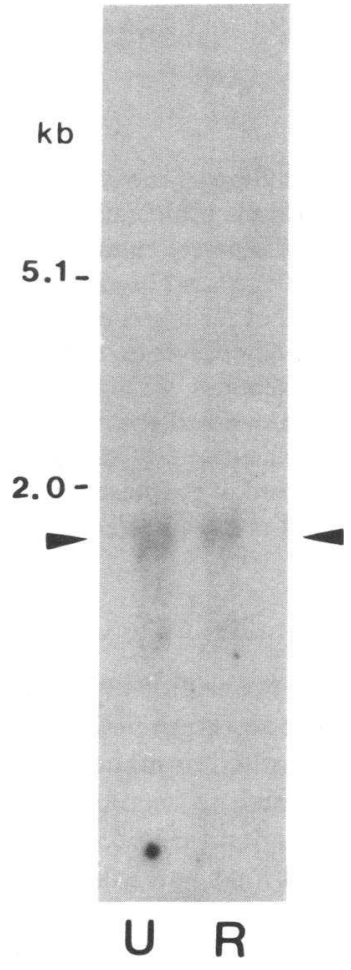

Figure 1. U 266 and RPMI 8226 myeloma cells lines feature IL-6 mRNA. $10 \mu \mathrm{g}$ total RNA from $\mathrm{U} 266(U)$ and RPMI $8226(R)$ cells was electrophoresed and blotted to nitrocellulose filters. Blot was hybridized with the IL-6 probe. A normal sized (arrows) mRNA is detected in both lines after a 3-d exposure of the film.

\section{Discussion}

In recent years much interest has centered on the role of peptide growth factors in regulating the development of normal cells or in tumorigenesis. The autocrine hypothesis suggests that one way in which a tumor may become autonomous is by production of growth factors for which it possesses functional receptors. Human MM appears to be a likely candidate for an autocrine tumor since malignant plasma cells display receptors for IL-6 and are able to secrete this lymphokine (4). Furthermore, the spontaneous proliferation of plasma cells is inhibited by antibodies to IL-6 (4). However, IL-6, although triggering plasma cell proliferation in approximately half of patients in
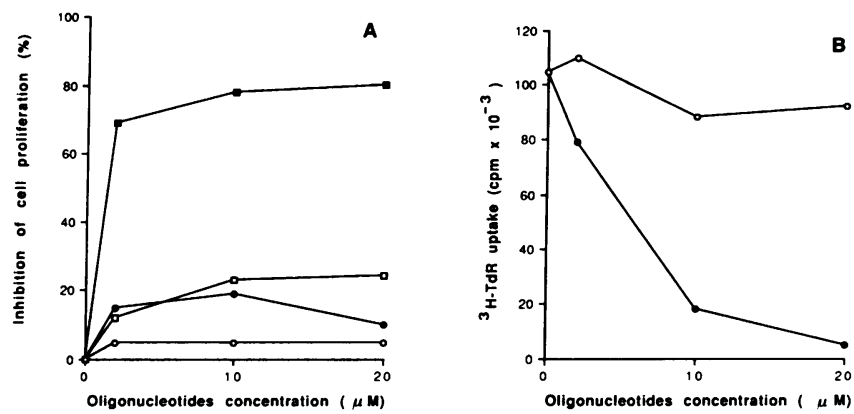

Figure 2. Dose-dependent inhibition of myeloma cells proliferation by IL- 6 antisense nucleotides. Cells were cultured for $48 \mathrm{~h}$ at $10^{5}$ cells $/ \mathrm{ml}$ of culture medium alone or in the presence of various concentrations of IL- 6 antisense (closed symbol) or IL- 6 control sense (open symbol) nucleotides. $(A)$ Percentage of inhibition in $\left[{ }^{3} \mathrm{H}\right]-\mathrm{TdR}$ uptake of $\mathrm{U} 266(\square, \square)$ and MOLT $-4(0, \bullet)$ cells. $(B)\left[{ }^{3} \mathrm{H}\right]-\mathrm{TdR}$ uptake by RPMI 8226 cells (cpm). 


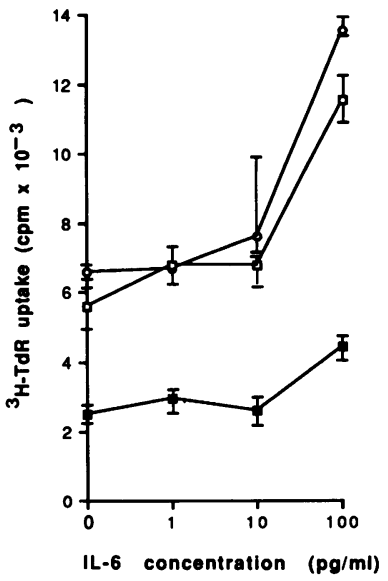

Figure 3. Addition of exogenous IL-6 increases the proliferation of U 266 cells. Cells were cultured for $48 \mathrm{~h}$ at $10^{5}$ cells $/ \mathrm{ml}$ in medium alone $(0)$ and in the presence of $20 \mu \mathrm{M}$ of IL- 6 antisense ( $)$ or IL-6 sense ( $\square$ ) nucleotides. Vertical bars represent the standard errors. A twofold increase in $\left[{ }^{3} \mathrm{H}\right]-\mathrm{TdR}$ uptake is observed in the presence of $100 \mathrm{pg} / \mathrm{ml}$ of rIL-6 in all culture conditions.

short-term cultures, cannot by itself allow the establishment of permanent cell lines (15). In addition, the secretion of IL-6 by tumor cells has been demonstrated in a limited number of patients only. Lastly, many cell types are able to secrete IL-6, suggesting a paracrine stimulation of malignant cells (5).

We studied two human myeloma cell lines and examined the role of IL-6 in their growth. U266 and RPMI 8226 cells secreted low amounts of IL-6 and exhibited a twofold increase in cell proliferation in the presence of exogenous IL-6. The addition of neutralizing antibodies to IL- 6 had no effects on the spontaneous cell proliferation. In contrast, an 80-95\% inhibition of proliferation was obtained in the presence of $20 \mu \mathrm{M}$ IL-6 antisense oligodeoxynucleotides.

These results provide definite evidence that IL-6 plays a central role in the growth of these myeloma cell lines and also suggest that the triggering signal may be internal to the cell. This would be in keeping with experimental models where internal activation of receptors by autocrine mechanisms may play a role in cell transformation (16-20). In particular, murine hematopoietic cells transfected with an IL-3 gene extended in the carboxy-terminal coding sequence with an oligonucleotide encoding for an endoplasmic reticulum retention signal, led to a growth factor-independent proliferation (17). The mechanism by which intracellular binding of receptors and not external triggering of the cells by growth factors can lead to transformation is still unclear $(18,19)$. Persistent interaction of receptors with their ligand in the Golgi apparatus or endoplasmic reticulum may potentially transmit a continuous mitogenic signal leading to initiation and maintenance of the transformed state.

Several lines of evidence suggest that IL-6 may be an example of such a transforming growth factor. For instance, transfection of the human IL-6 gene in murine plasmacytoma or hybridoma led to increased tumorigenicity $(21,22)$. On the other hand, IL-6 gene transgenic mice exhibit a striking plasmacytosis but no transplantable plasma cell tumor could be obtained (23). It is conceivable that acquired, and still undefined, additional genetic changes might render some B cells more susceptible to autonomous growth depending upon intracellular growth factor stimulation. Of note, the IL-6 and IL-6R genes from both lines which were studied exhibited no detectable structural alterations as assessed by Southern analysis with several restriction enzymes (data not shown).
These findings are particularly relevant to the biology of human MM. The establishment of myeloma cell lines is quite difficult. Recent studies taking advantage of the role of various growth factors including IL-6 but also granulocyte macrophage colony-stimulating factor or monocyte-derived conditioned medium allowed the production of factor-dependent cell lines that eventually grow autonomously $(15,24)$. Most of these lines arise from plasma cells obtained in patients with aggressive, extra osseous myelomas. An appealing hypothesis would be that the IL-6 autocrine myeloma cell lines that were used in our study are representative of the so-called myeloma stem cells (25). These cells give rise in vitro to malignant colonies (25) and are believed to replenish the large pool of nondividing plasma cells. The latter may be triggered to proliferate by IL-6 external stimulation only. This model would be compatible with most published data on the role of IL-6 in multiple myeloma. Interestingly, it has been shown that the mature, nonproliferating, progeny of leukemic myeloid blast cells produce the growth factor that stimulates the blast cells (26). Finally, it should be emphasized that therapeutic trials with monoclonal antibodies designed to neutralize IL-6 or to compete with this lymphokine for IL-6R occupancy will likely fail to eradicate IL-6 autocrine cells such as those we have characterized here.

\section{References}

1. Kishimoto, T. 1989. The biology of Interleukin-6. Blood. 74:1-10.

2. Nordan, R., and M. Potter. 1986. A macrophage-derived factor required by plasmacytomas for survival and proliferation in vitro. Science (Wash. DC). 233:566-569.

3. Van Damme, J., G. Opdenakker, R. J. Simpson, M. R. Rubira, S. Cayphas, A. Vink, A. Billiau, and J. Van Snick. 1987. Identification of the human 26-kD protein, interferon $\beta 2$ (IFN- $\beta 2$ ), as a B cell hybridoma/plasmacytoma growth factor induced by interleukin 2 and tumor necrosis factor. J. Exp. Med. 165:914919.

4. Kawano, M., T. Hirano, T. Matsuda, T. Taga, Y. Horii, K. Iwato, H. Asaoku, B. Tang, O. Tanabe, $H$. Tanaka, et al. 1988. Autocrine generation and requirement of BSF-2/IL-6 for human multiple myelomas. Nature (Lond.). 332:83-85.

5. Klein, B., X. G. Zhang, M. Jourdan, J. Content, F. Houssiau, L. Aarden, M. Piechaczyk, and R. Bataille. 1989. Paracrine rather than autocrine regulation of myeloma-cell growth and differentiation by interleukin-6. Blood. 73:517-526.

6. Nilsson, K., A. Bennich, S. G. O. Johansson, and J. Pontent. 1970. Established immunoglobulin producing myeloma (IgE) and lymphoblastoid (IgG) cell lines from an IgE myeloma patient. Clin. Exp. Immunol. 7:477-480.

7. Moore, G. E., J. W. Marbell, L. K. Woods, K. T. Morgan, and T. V. Semple. 1982. RPMI 8226, a human myeloma cell line: an update. Proc. Am. Assoc. Cancer Res. 33:126-129.

8. Yasukawa, K., T. Hirano, Y. Watanabe, K. Muratahi, T. Matsuda, S. Nakai, and T. Kishimoto. 1987. Structure and expression of human B cell stimulatory factor-2 (BSF-2/IL-6) gene. EMBO (Eur. Mol. Biol. Organ.) J. 6:2939_ 2945.

9. Miles, S. A., A. R. Rezai, J. F. Salazar-Gonzalez, M. Van der Meyden, R. H. Stevens, D. M. Logan, R. T. Mitsuyasu, T. Taga, T. Hirano, T. Kishimoto, and O. Martinez-Maza. 1990. AIDS Kaposi sarcoma-derived cells produce and respond to interleukin 6. Proc. Natl. Acad. Sci. USA. 87:4068-4072.

10. Blin, N., and D. W. Stafford. 1976. A general method for isolation of high molecular weight DNA from eukaryotes. Nucleic Acids Res. 3:2303-2309.

11. Chirgwin, J. M., A. E. Przybyla, R. J. MacDonald, and W. J. Rutter. 1979. Isolation of biologically active ribonucleic acid from sources enriched in ribonuclease. Biochemistry. 18:5294-5299.

12. Southern, E. 1975. Detection of specific sequences among DNA fragments separated by gel electrophoresis. J. Mol. Biol. 98:503-517.

13. Tsapis, A., M. Bentaboulet, P. Pellet, E. Mihaesco, D. Thierry, M. Seligmann, and J. C. Brouet. 1989. The productive gene for $\alpha-H$ chain disease protein MAL is highly modified by insertion-deletion processes. J. Immunol. 143:38213827.

14. Feinberg, A., and B. Vogelstein. 1983. A technique for radiolabeling DNA restriction endonuclease fragments to high specific activity. Anal. Biochem. 132:6-13. 
15. Klein, B., X G. Zhang M. Jourdan, J. M. Boiron, M. Portier, Z. Y. Lu, J. Wijdenes, J. Brochier, and R. Bataille. 1990. Interleukin 6 is the central tumor growth factor in vitro and in vivo in multiple myeloma. Eur. Cytokine Network. I:193-201.

16. Browder, T. M., J. S. Abrams, P. M. C. Wong, and A. W. Nienhuis. 1989. Mechanism of autocrine stimulation in hematopoietic cells producing Interleukin-3 after retrovirus-mediated gene transfer. Mol. Cell. Biol. 9:204-213.

17. Dunbar, C. E., T. M. Browder, J. S. Abrams, and A. W. Nienhuis. 1989. $\mathrm{COOH}$-terminal-modified Interleukin-3 is retained intracellularly and stimulates autocrine growth. Science (Wash. DC). 245:1493-1496.

18. Keating, M. T., and L. T. Williams. 1988. Autocrine stimulation of intracellular PDGF receptors in v-sis-transformed cells. 239:914-916.

19. Bejcek, B. E., D. Y. Li, and T. F. Deuel. 1989. Transformation by v-sis occurs by an internal autoactivation mechanism. Science (Wash. DC). 245:14961499.

20. Huang, S. S., and J.S. Huang. 1988. Rapid turnover of the platelet-derived growth factor receptor in sis-transformed cells and reversal by suramin. J. Biol. Chem. 263:12608-12618.

21. Vink, A., P. Coulie, G. Warnier, J. C. Renauld, M. Stevens, D. Donckers, and J. Van Snick. 1990. Mouse plasmacytoma growth in vivo: enhancement by interleukin 6 (IL-6) and inhibition by antibodies directed against IL- 6 or its receptor. J. Exp. Med. 172:997-1000.

22. Scala, G., I. Quinto, M. R. Ruocco, A. Arcucci, M. Mallardo, P. Caretto, G. Forni, and S. Venuta. 1990. Expression of an exogenous interleukin 6 gene in human Epstein Barr virus B cells confers growth advantage and in vivo tumorigenicity. J. Exp. Med. 172:61-68.

23. Suematsu, S., T. Matsuda, K. Aozasa, S. Akira, N. Nakano, S. Ohno, J. I. Miyazaki, K. I. Yamamura, T. Hirano, and T. Kishimoto. 1989. IgGI plasmacytosis in interleukin 6 transgenic mice. Proc. Natl. Acad. Sci. USA. 86:7547-7551.

24. Shimizu, S., R. Yoshioka, Y. Hirose, S. Sugai, J. Tachibana, and S.

Konda. 1989. Establishment of two interleukin 6 (B cell stimulatory factor $2 /$ interferon $\beta_{2}$ )-dependent human bone marrow-derived myeloma cell lines. J. Exp. Med. 169:339-344.

25. Hamburger, A. W., and S. E. Salmon. 1977. Primary bioassay of human myeloma stem cells. J. Clin. Invest. 60:846-854.

26. Laker, C., C. Stocking, U. Bergholz, N. Hess, J. F. De Lamarter, and W. Ostertag. 1987. Autocrine stimulation after transfer of the granulocyte/macrophage colony-stimulating factor gene and autonomous growth are distinct but interdependent steps in the oncogenic pathway. Proc. Natl. Acad. Sci. USA. 84:8458-8462. 